\title{
Dietary protein and energy supplies differentially affect resistance to parasites in lactating mammals
}

\author{
Panagiotis Sakkas ${ }^{1}$, Jos G. M. Houdijk ${ }^{1 *}$, Leigh A. Jones ${ }^{1} \dagger$, Dave P. Knox ${ }^{2}$ and Ilias Kyriazakis ${ }^{1,3} \ddagger$ \\ ${ }^{1}$ Animal Health Group, Scottish Agricultural College, West Mains Road, Edinburgh EH9 3JG, UK \\ ${ }^{2}$ Parasitology Division, Moredun Research Institute, Penicuik EH26 OPZ, UK \\ ${ }^{3}$ Veterinary Faculty, University of Thessaly, PO Box 199, 43100 Karditsa, Greece \\ (Received 9 November 2010 - Revised 16 February 2011 - Accepted 25 February 2011 - First published online 31 May 2011)
}

\section{Abstract}

Periparturient relaxation of immunity (PPRI) to parasites in mammals results in higher worm burden and worm egg excretion and may have a nutritional basis. Nippostrongylus brasiliensis re-infected lactating rats fed low-crude protein (CP) diets show an augmented degree of PPRI compared with their high CP-fed counterparts. However, such effects of CP scarcity have been confounded by metabolisable energy (ME) scarcity due to increased intake of the high-CP foods. Here, we independently assessed the effects of dietary CP and ME scarcity on the degree of PPRI. Second, parity rats were infected with $N$. brasiliensis larvae before mating. Upon parturition, dams were allocated to one of six feeding treatments (1-6), consisting of two levels of dietary ME supply, each with three levels of CP supply. On day 2 of lactation, dams were either re-infected with $1600 \mathrm{~N}$. brasiliensis larvae or sham-infected with PBS, while litter size was standardised at ten pups. Dams and litters were weighed daily until either day 8 or 11 of lactation, when worm burdens were assessed as a proxy for PPRI. Increased CP and ME supply independently improved lactational performance. While ME supply did not affect parasitism, increasing CP supply reduced worm burden and the percentage of female worms in the small intestine; the latter was especially pronounced at the lower level of ME supply. The present results support the view that PPRI to parasites may be sensitive to CP scarcity, but not to moderate ME scarcity.

Key words: Energy intake: Lactation: Nematodes: Protein nutrition: Rats

During their life cycle, mammals acquire immunity towards gastrointestinal nematode (GIN) parasites, as they are continuously exposed to their infective forms. However, the effective expression of this acquired immunity can break down during certain points in time, e.g. during the periparturient period $^{(1)}$. Such a periparturient relaxation of immunity (PPRI) plays an important role in the epidemiology of GIN infections. PPRI is associated with a higher GIN burden and nematode egg excretion ${ }^{(2,3)}$, and as such the periparturient host is a major source of infection for its parasite-naïve offspring.

A nutrient partitioning framework has identified the hypothesis that PPRI has a nutritional basis: scarce nutrients may be preferentially used to meet the elevated nutritional demands of the reproductive effort at the expense of the immune response during the periparturient period $^{(4)}$. Consequently, at times of nutrient scarcity, increased nutrient supply would be expected to reduce the degree of PPRI to parasites and lead to reduced worm burden and worm egg excretion. There is indeed a significant body of evidence to support the view that protein supplementation in mammals, such as small ruminants, reduces the degree of PPRI ${ }^{(5,6)}$. Similarly, feeding foods with higher crude protein (CP) content to lactating rodents exposed to the GIN Nippostrongylus brasiliensis has also resulted consistently in reduced worm burden ${ }^{(7-9)}$ However, in the above studies, the animals were fed ad libitum and the increased dietary protein contents resulted in increased feed intake per se, which confounded the effects of protein supply with other dietary factors such as energy supply. It has been suggested that dietary protein and energy deficiency may have different effects on host defence mechanisms ${ }^{(10)}$, while evidence from ruminant studies

Abbreviations: CP, crude protein; EIC, eggs in the colon; FEC, faecal egg count; GIN, gastrointestinal nematode; ME, metabolisable energy; PBW, parturition body weight; PPRI, periparturient relaxation of immunity.

*Corresponding author: J. Houdijk, fax +44 131 5353121, email jos.houdijk@sac.ac.uk

†Present address: Singapore Immunology Network (SIgN), 8A Biomedical Grove, Immunos Building No. 3-4, BIOPOLIS 138648, Singapore.

$\ddagger$ Present address: School of Agriculture, Food and Rural Development, Newcastle University, NE1 7RU, UK. 
suggests that moderate protein, but not energy deficiency, may increase the degree of periparturient parasitism ${ }^{(11)}$. In ruminants, however, the effects of energy and protein nutrition may be difficult to assess separately due to the modifying role of the rumen ${ }^{(1)}$. Since such confounding effects can be readily avoided in non-ruminants, our objective was to dissect, for the first time in a monogastric model, the effects of moderate energy and protein restriction on PPRI to GIN parasites. We hypothesised that, at times of dietary protein and energy scarcity, increasing protein supply would be more effective in reducing the degree of PPRI than increasing energy supply.

\section{Experimental methods}

\section{Animals, housing and feeding strategy during gestation}

The experiment described below was approved by the Scottish Agricultural College Ethics Review Committee (ED AE 24/2007) and carried out under Home Office authorisation (PPL 60/3626). One hundred and sixteen second-parity female rats were housed in a room, where ambient temperature was maintained at $21^{\circ} \mathrm{C}$, relative humidity ranged from 45 to $65 \%$ and artificial lighting was provided between 08.00 and 18.00 hours. The rats were individually housed in solidbottomed cages, with fresh sawdust provided weekly. Shredded plastic bubble wrapping for nesting material was provided $3 \mathrm{~d}$ before the expected parturition date. Wirebottomed cages were used during mating and for faeces collection during the primary infection, as described previously $^{(12)}$. For mating, female rats were placed with a proven male breeder and mating was confirmed through the presence of a vaginal plug.

Until mating was confirmed, the rats were given ad libitum access to standard rat chow (Rat and Mouse no. 3; Special Diet Services, Witham, Essex, UK). After mating was confirmed, the rats were given ad libitum access to a high-protein food, with $210 \mathrm{~g}$ digestible $\mathrm{CP}$ and $16.4 \mathrm{MJ}$ metabolisable energy (ME) $/ \mathrm{kg} \mathrm{DM}$ until $10 \mathrm{~d}$ into gestation to allow for establishment of pregnancy and placental development. The rats were then fed with a low-protein food, containing $60 \mathrm{~g} \mathrm{CP}$ and $17 \cdot 3 \mathrm{MJ} \mathrm{ME} / \mathrm{kg} \mathrm{DM}$, which was continued until parturition. This feeding protocol was used to reduce body protein reserves during the second half of gestation in order to maximise the degree of protein scarcity during lactation when the rats would be fed low-protein foods ${ }^{(7,13)}$.

\section{Feeding treatments}

Six feeding treatments ${ }^{(1-6)}$ were designed, consisting of restrictedly feeding one of two levels of predetermined ME supply at one of three levels of predetermined CP supply (Fig. 1). Feeding treatments $1-3$ and 4-6 were calculated to supply 1.05 and $1.40 \mathrm{MJ} \mathrm{ME} / \mathrm{kg}$ parturition body weight (PBW) per $\mathrm{d}$, respectively. These planes of ME nutrition were $90 \%$ of the previously observed mean ME intakes on low- and high-protein foods, respectively ${ }^{(8)}$. In addition, CP supply was calculated to increase incrementally from scarce to more than adequate at each level of ME supply. This was

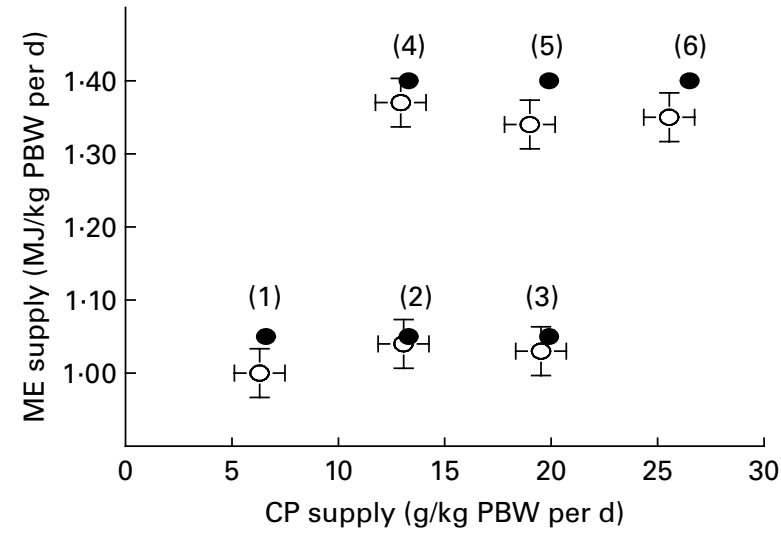

Fig. 1. Planned $(\bullet)$ and achieved $(\bigcirc$, with $S E)$ dietary supply of metabolisable energy (ME, MJ/kg parturition body weight (PBW) per d) and crude protein (CP, g/kg PBW per d) from six experimental feeding treatments over the first $11 \mathrm{~d}$ of lactation in rats, re-infected with Nippostrongylus brasiliensis.

$6.6,13.3$ and $19.9 \mathrm{~g} / \mathrm{kg}$ PBW per $\mathrm{d}$ for the low ME level, and $13 \cdot 3,19 \cdot 9$ and $26.5 \mathrm{~g} / \mathrm{kg}$ PBW per $\mathrm{d}$ for the high ME level treatments. These $\mathrm{CP}$ allowances were chosen to reflect the range of achieved mean daily CP intake of similar foods in previous experiments under ad libitum feeding ${ }^{(7-9)}$ using dam PBW as a scaling factor. Variation in dietary CP content was achieved through the isoenergetic exchange of casein with digestible carbohydrates (starch/sucrose). The resulting composition of the experimental foods is presented in Table 1.

Foods were offered on a daily basis in increasing amounts during lactation, reflecting the natural increase in food intake observed in previous experiments with this animalparasite model system ${ }^{(7-9)}$. We omitted a priori feeding treatments with very low or high CP:ME ratios that would jeopardise food intake, as earlier work has shown that voluntary intake on such foods was unacceptably low in lactating animals $^{(14,15)}$. Thus, our experimental design can be described as having an incomplete $4 \times 2$ factorial arrangement (Fig. 1).

\section{Infection protocol}

All rats received a primary infection of 1600 third-stage infective larvae of $N$. brasiliensis on day -37 (with day 0 as mean achieved parturition date), which were suspended in $0.5 \mathrm{ml}$ sterile PBS that was subcutaneously injected in the hind leg. A secondary infection of 1600 third-stage infective larvae $N$. brasiliensis was administered on day 2 to a subgroup of rats. At the same time, control rats (primary infected only) were sham-infected through subcutaneous injection of $0.5 \mathrm{ml}$ sterile PBS only.

\section{Experimental design}

The effects of the six feeding treatments used were assessed on lactational performance and parasitological variables on days 8 and 11 of lactation (corresponding to days 6 and 9 post secondary infection, respectively). The two sampling time points post-secondary infection were included, as previous data ${ }^{(8)}$ suggested that the nutritional sensitivity of host resistance may differ over time. All rats in these twelve feeding 
Table 1. Composition and analysis of the experimental food used during lactation

\begin{tabular}{lcrrrrr}
\hline Experimental foods & 1 & 2 & 3 & 4 & 5 & 6 \\
\hline Ingredients (g/kg fresh) & & & & & & \\
Casein & 102 & 204 & 306 & 153 & 229 & 306 \\
Methionine & 1 & 2 & 3 & 2 & 2 & 3 \\
Starch & 343 & 275 & 206 & 309 & 257 & 206 \\
Sucrose & 172 & 137 & 103 & 154 & 129 & 103 \\
Maize oil & 141 & 141 & 141 & 141 & 141 & 141 \\
Vitamin & 47 & 47 & 47 & 47 & 47 & 47 \\
Minerals & 47 & 47 & 47 & 47 & 47 & 47 \\
Maize starch & 46 & 46 & 46 & 46 & 46 & 46 \\
Choline & 7 & 7 & 7 & 7 & 7 & 7 \\
Lecithin & 2 & 2 & 2 & 2 & 2 & 2 \\
Alphacel & 94 & 94 & 94 & 94 & 94 & 94 \\
Analysed chemical composition & & & & & & \\
DM (g/kg fresh matter) & $715 \cdot 2$ & $656 \cdot 5$ & $604 \cdot 0$ & $696 \cdot 6$ & $644 \cdot 4$ & $612 \cdot 5$ \\
ME (MJ/kg DM) & $15 \cdot 9$ & $15 \cdot 9$ & $15 \cdot 9$ & $15 \cdot 9$ & $15 \cdot 9$ & $15 \cdot 9$ \\
CP (g/kg DM) & 99 & 191 & 285 & 142 & 213 & 285 \\
Ash (g/kg DM) & $38 \cdot 3$ & $38 \cdot 4$ & $40 \cdot 6$ & 38.5 & $39 \cdot 0$ & $40 \cdot 6$ \\
Acid-detergent fibre (g/kg DM) & $74 \cdot 7$ & $78 \cdot 7$ & $91 \cdot 8$ & $74 \cdot 8$ & $78 \cdot 7$ & $91 \cdot 8$ \\
Diethyl ether extract (g/kg DM) & 162 & 158 & 154 & 154 & 153 & 154 \\
\hline
\end{tabular}

$\mathrm{ME}$, metabolisable energy; $\mathrm{CP}$, crude protein

${ }^{*}$ Food ME contents was calculated by multiplying its content of protein (casein), digestible carbohydrates (starch, sucrose and maize starch) and fat (maize oil) with the ME contents of protein $(17 \mathrm{MJ} / \mathrm{kg})$, carbohydrates $(17 \mathrm{MJ} / \mathrm{kg})$ and fat $(38 \mathrm{MJ} / \mathrm{kg})^{(58)}$.

treatment-endpoint combinations (six feeding treatments $\times$ two endpoints) received secondary infection. In addition, control rats that did not receive secondary infection were included until day 8 of lactation for each feeding treatment to assess the effect of re-infection on lactational performance (dam and litter weight gain), i.e. six additional control treatments. This resulted in a total of eighteen treatments. Rats blocked for PBW were randomly allocated to these eighteen treatments on the morning of the parturition date. Total sample size aimed for was seven for infected rats and six for control rats. However, the minimum realised sample size for each of the eighteen resulting treatments was five.

\section{Measurements}

Body weight and food intake. The rats were weighed daily throughout the experiment, and daily weights taken postparturition was used to calculate lactational dam weight gain. The pups were counted and the whole litter was weighed daily from day 0 of lactation. Litter size was standardised at twelve pups on day 1 and this was further reduced to ten pups on day 2 of lactation to ensure pup survival and to have equal initial nutrient demands. Litter weight from day 2 onwards was used to calculate litter weight gain during lactation. Because of the restricted feeding regimen, refusals were not expected during lactation. However, food intake was measured daily and any refusals observed during the lactation period were weighed in order to calculate mean achieved CP and ME intake. Foods offered during lactation were sampled during their preparation for the analysis of DM, CP (Kjeldahl-N × 6.38), diethyl ether extract, ash and acid-detergent fibre (Table 1).

Faecal egg counts. A faecal egg count (FEC, in eggs/g of fresh faeces) was performed $7 \mathrm{~d}$ after the primary infection (day -30) to confirm the presence of infection. A second
FEC was performed on day -23 to confirm that the expected parasite expulsion had taken place. To this effect, faeces were collected through overnight housing on bottom-wired cages $^{(12)}$ and FEC were performed using a modified saturated salt flotation method ${ }^{(16)}$.

Worm burden and nematode eggs in the colon. The rats were killed through gradually increasing ambient $\mathrm{CO}_{2}$ concentration, followed by $\mathrm{CO}_{2}$ asphyxiation for parasitological assessment (see later) and immune responses ${ }^{(17)}$. The small intestine was removed and stored in formaldehyde for subsequent worm burden assessment (number, sex and stage of maturity according to worm morphology). The contents of the large intestine were weighed and assessed for worm eggs, as described for FEC above. This was then multiplied by the weight of the large intestinal contents to obtain the total number of nematode eggs in the colon (EIC). The latter measure is preferred over the FEC equivalent of the colon contents, as feeding treatments used could have biased colon contents volume, and thus the concentration of EIC contents.

\section{Calculations and statistical analysis}

Data were analysed using restricted maximum likelihood, to account for the incomplete $4 \times 2$ factorial design of the $\mathrm{CP}-\mathrm{ME}$ combinations used. The effects of CP supply, ME supply, endpoint and their two-and three-way interactions were assessed on dam body weight gain, litter weight gain, worm burden, percentage of female worms and EIC. In order to investigate for the effect of infection per se, a separate restricted maximum likelihood analysis was used to assess the effects of CP supply, ME supply, infection status and their two and three-way interactions on dam body weight gain and litter growth until day 8 of lactation. For both statistical assessments, 
interactions that did not approach significance at $P<0.05$ were omitted from the final models used.

Because of their skewed nature, the EIC and worm burden were transformed according to $\log (n+1)$ to normalise data before statistical analysis. These data are reported as back-transformed means with their 95\% CI, as described previously ${ }^{(7)}$. All statistical analyses were performed using Genstat 11 for Windows release 11.1, 2008 (VSN International, Hemel Hempstead, Hertfordshire, UK).

\section{Results}

Faecal egg counts during the primary infection and performance until parturition

FEC taken on day -37 and - 30 averaged 3563 (95\% CI 351, 319) eggs/g and 0 (95\% CI 0,0) eggs/g, respectively. Initial mean body weight was 345 (SE 4.0 ) g. During the first $10 \mathrm{~d}$ of gestation, the rats grew from 355 (SE 3.6) to 383 (SE 4.3) g and had an average DM intake of $20.6(\operatorname{se} 0.40) \mathrm{g} / \mathrm{d}$. From then onwards and until parturition, the pregnant rats continued to gain weight to a mean of 451 (SE 5.1) g and had an average DM intake of 18.7 (SE 0.51$) \mathrm{g} / \mathrm{d}$, which dropped to an average of $7 \cdot 1$ (SE 0.62$) \mathrm{g} / \mathrm{d}$ just before parturition. Dam mean PBW averaged 360 (SE 4.6) g, mean litter size averaged 14.2 pups (SE $0 \cdot 27) \mathrm{g}$ and mean litter weight averaged $74 \cdot 1$ (SE 0.99) g.

\section{Achieved metabolisable energy and crude protein intake}

Fig. 1 shows the expected and achieved least squares mean intake of ME and CP over the $11 \mathrm{~d}$ lactating period/kg PBW per d. Small numbers of feed refusal were observed for each feeding treatment. Consequently, target $\mathrm{CP}$ and ME supply were not exactly met. However, as intended, feeding treatment did not significantly affect achieved ME intake, within the low $(P=0 \cdot 130)$ and the high level of ME supply $(P=0.897)$. Infection did not affect mean achieved ME intake $(P=0 \cdot 290)$ and $\mathrm{CP}$ intake $(P=0 \cdot 738)$.

\section{Dam weight gain}

The effects of feeding treatments (Fig. 2(a)) and infection for each feeding treatment (Fig. 2(b)) on daily dam weight gain were shown. Dam weight gain was significantly affected by dietary CP supply $(P<0 \cdot 001)$ and ME supply $(P<0 \cdot 001)$, but not by the endpoint $(P=0.401$; data not shown). Dams at a low level of ME supply lost more weight than dams at a high level of ME supply. An increasing level of CP supply resulted in increased dam weight gain at both levels of $\mathrm{ME}$ supply (Fig. 2(a)). Infection did not affect dam weight gain (Fig. 2(b); $P=0.494)$, while no significant interactions among any of the factors involved were observed $(P>0 \cdot 10)$.

\section{Litter weight gain}

The effects of feeding treatments (Fig. 3(a)) and infection for each feeding treatment (Fig. 3(b)) on daily litter weight gain

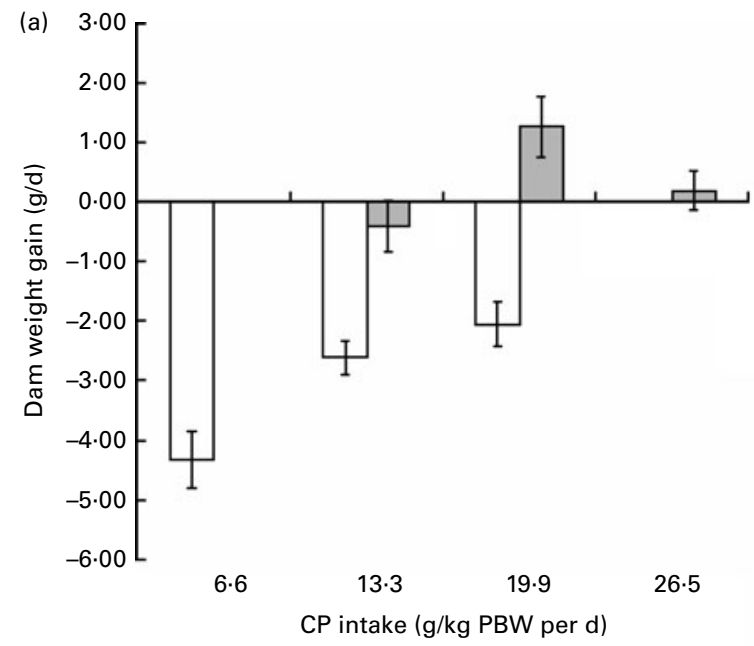

(b)

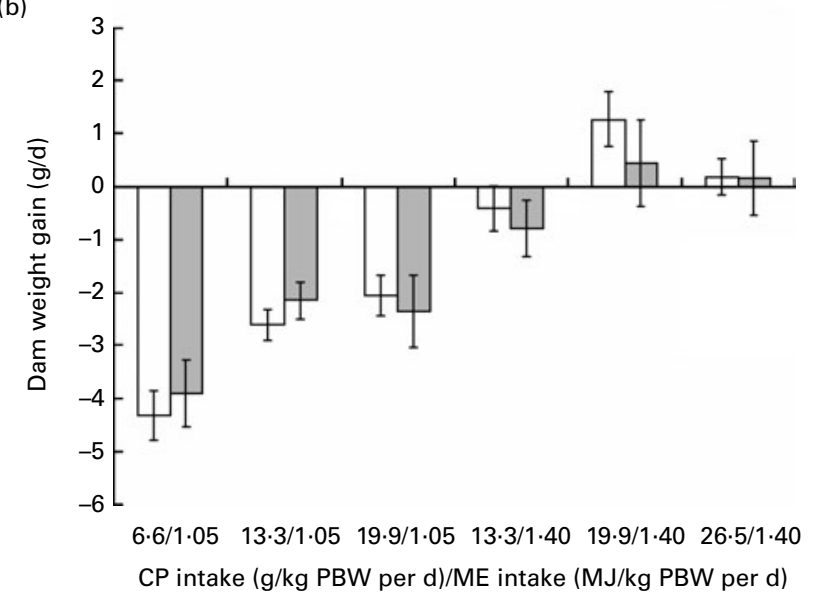

Fig. 2. Dam weight gain across four levels of dietary supply of crude protein (CP) and two levels of metabolisable energy (ME, 1.05 and $1.40 \mathrm{MJ} / \mathrm{kg}$ parturition body weight $(\mathrm{PBW}) / \mathrm{d}$ ) over the first $11 \mathrm{~d}$ of lactation in rats (a) re-infected with Nippostrongylus brasiliensis ( $\square$, low energy; $\square$, high energy) and (b) across these feeding treatments for infected and non-infected control lactating rats ( $\square$, infected; $\square$, control). Values are means with their standard errors represented by vertical bars.

are shown. Litter weight gain was affected by CP supply $(P<0 \cdot 001)$ and ME supply $(P=0 \cdot 011)$, but not by the endpoint $(P=0 \cdot 247$; data not shown). Litters from low ME dams gained less weight than litters from high ME dams. An increasing level of CP supply resulted in higher litter weight gain at both levels of ME supply (Fig. 3(a)). Infection status (Fig. 3(b)) significantly affected litter weight gain $(P=0.015)$. Although the interaction between CP supply, ME supply and infection status was not formally significant $(P=0 \cdot 113)$, litters of infected dams allocated to feeding treatments 1 and 2 showed lower weight gain than their non-infected counterparts.

\section{Total worm burden, eggs in colon and worm burden composition}

The effects of feeding treatments on total worm burden for day 8 (Fig. 4(a)) and day 11 of lactation (Fig. 4(b)) were shown, while Fig. 5 shows such effects for EIC on the same 

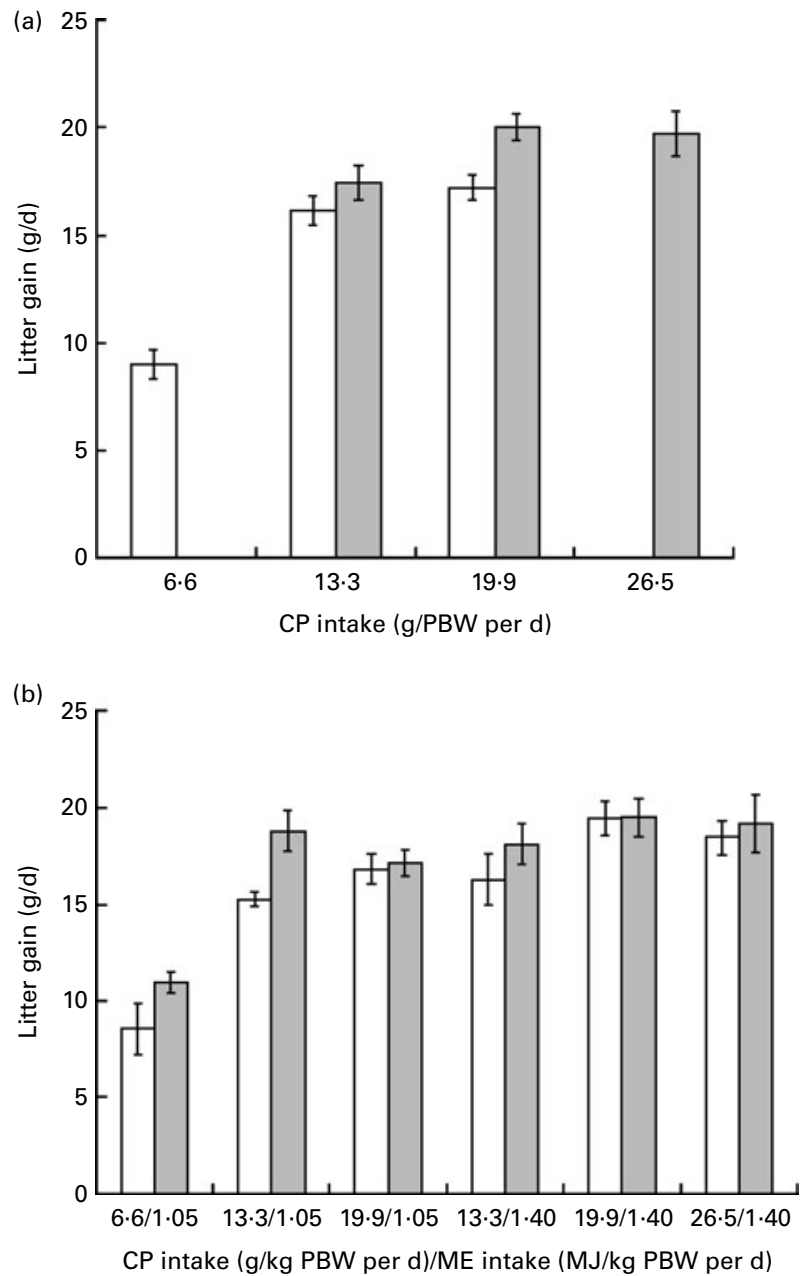

Fig. 3. Litter weight gain across four levels of dietary supply of crude protein (CP) and two levels of metabolisable energy (ME, 1.05 and $1.40 \mathrm{MJ} / \mathrm{kg}$ parturition body weight (PBW per d) over the first $11 \mathrm{~d}$ of lactation in rats reinfected with (a) Nippostrongylus brasiliensis ( $\square$, low energy; $\square$, high energy) and (b) across these feeding treatments for infected and non-infected control lactating rats $(\square$, infected; $\square$, control). Values are means with their standard errors represented by vertical bars.

days. Total worm burden was significantly affected by CP supply $(P=0.023)$ and endpoint $(P=0.013)$, but were not influenced by ME supply $(P=0 \cdot 155)$. Worm burden decreased with increasing level of CP supply at both levels of ME supply and was lower on day 11 than on day 8 of lactation (Fig. 4(a) and (b)). Although Fig. 4 suggests that these effects of $\mathrm{CP}$ supply were more pronounced on day 8 than on day 11 , this interaction was not formally significant $(P=0 \cdot 248)$. EIC were not affected by dietary $\mathrm{CP} \quad(P=0 \cdot 204)$ and $\mathrm{ME}$ $(P=0.720)$ supply, which were significantly higher on day 11 than on day 8 (Fig. 5(a) and (b); $P=0.004$ ). There were no significant interactions between any of the above factors for EIC $(P>0 \cdot 10)$. Fig. 6 shows the percentage of female worms in the worm burden. ME supply $(P=0.470)$ and endpoint $(P=0 \cdot 161)$ did not affect worm burden composition. However, increasing CP supply reduced the percentage of female worms $(P=0.049)$, while the magnitude of this effect was greater at the lower level of ME supply ( $P=0 \cdot 022$; Fig. 6).

\section{Discussion}

Previous studies carried out with this rodent-nematode parasite model have consistently shown that reducing nutrient scarcity through increasing dietary $\mathrm{CP}$ content during lactation results in a reduced degree of parasitism ${ }^{(7-9)}$. In these studies, ad libitum feeding of high-CP foods resulted in reduced worm burden, but because food intake of high-CP foods increased, improved resistance could have arisen from the increased intake of any nutrient and/or energy. The present experiment aimed to account for this uncertainty by testing the hypothesis that parasitism during lactation is sensitive to $\mathrm{CP}$ supply per se by increasing levels of dietary CP supply at constant levels of ME supply. At the same time, the design allowed us to assess whether a moderate dietary ME restriction compromises lactating host resistance to parasites. We discuss our result that $\mathrm{CP}$ supply, but not ME supply, affects lactational resistance to $N$. brasiliensis. It is unlikely that the incomplete $4 \times 2$ factorial design used (Fig. 1) biased our conclusions; re-analysis of the
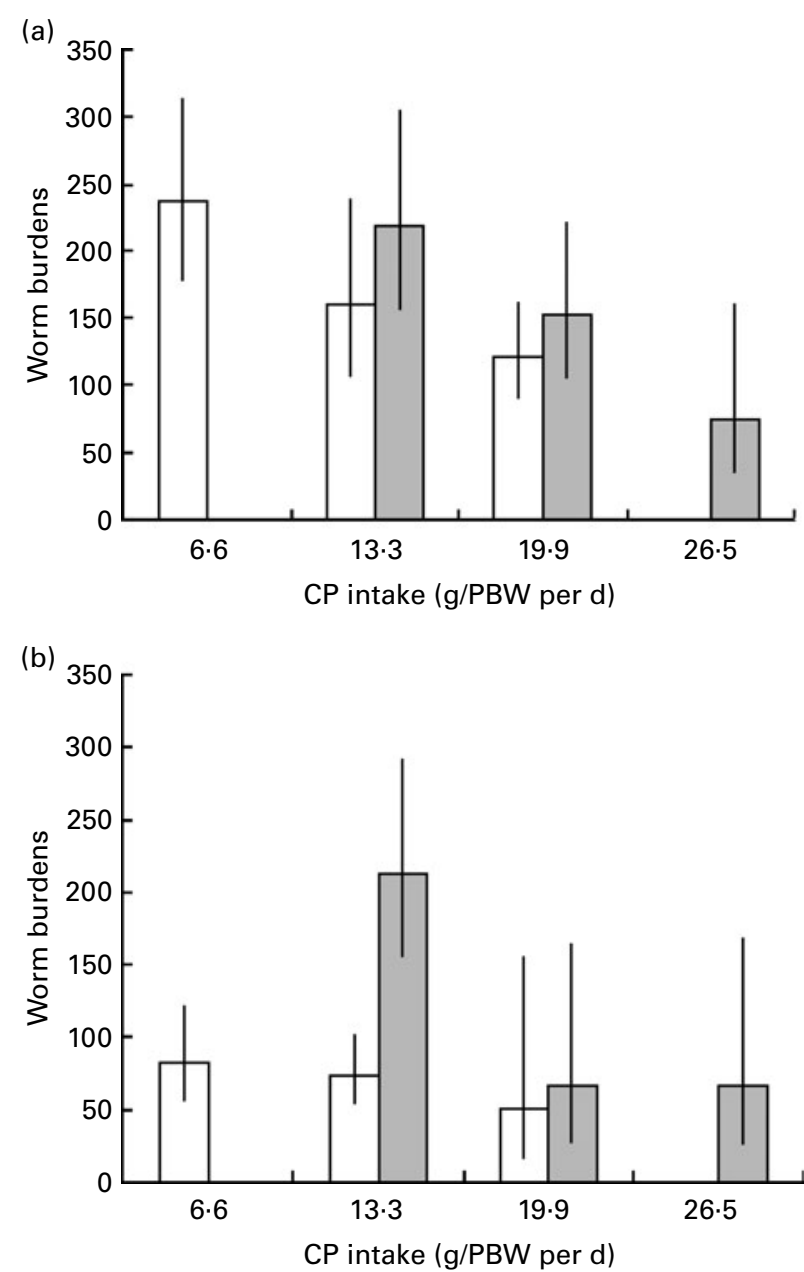

Fig. 4. Backtransformed mean worm burden, with backtransformed lowe and upper limits of transformed error bars as $95 \% \mathrm{Cl}$, taken on (a) day 8 ( $\square$, low energy; $\square$, high energy) and (b) day 11 ( $\square$, low energy; $\square$, high energy), following re-infection with Nippostrongylus brasiliensis on day 2 of lactation in rats fed four levels of dietary crude protein (CP) and two levels of metabolisable energy supply $(1.05$ and $1.40 \mathrm{MJ} / \mathrm{kg}$ parturition body weight (PBW) per d). 

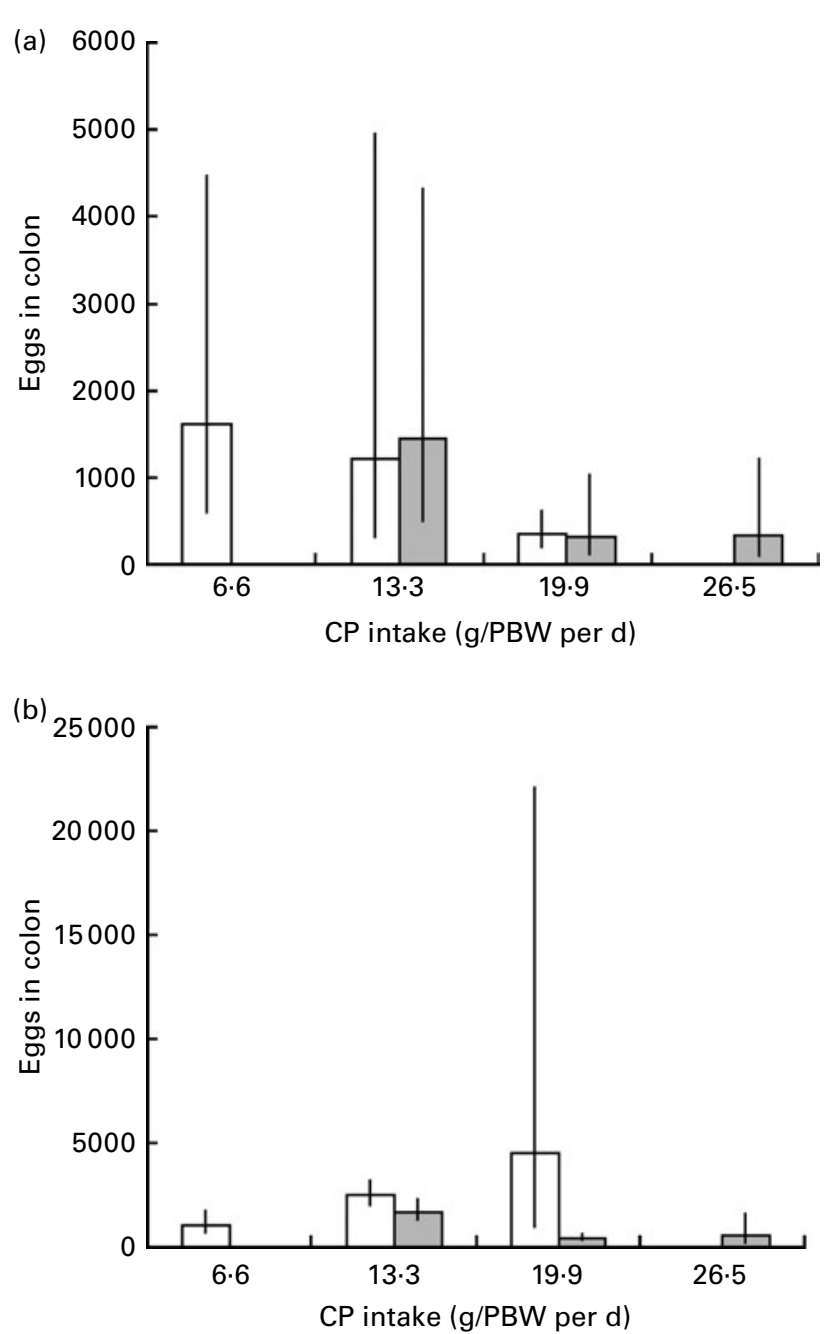

Fig. 5. Backtransformed mean total eggs in colon, with backtransformed lower and upper limits of transformed error bars as $95 \% \mathrm{Cl}$, taken on (a) day 8 ( $\square$, low energy; $\square$, high energy) and (b) day 11 ( $\square$, low energy; $\square$, high energy), following re-infection with Nippostrongylus brasiliensis on day 2 of lactation in rats fed four levels of dietary crude protein (CP) and two levels of metabolisable energy supply $(1.05$ and $1.40 \mathrm{MJ} / \mathrm{kg}$ parturition body weight (PBW) per d).

data omitting those arising from feeding treatments 1 and 6, thus addressing our hypothesis with a balanced $2 \times 2$ factorial design, confirmed that worm burden was affected by increased CP supply $(P=0.035)$ and not by ME supply $(P=0 \cdot 174)$, and although the effects of $\mathrm{CP}$ supply on worm burden were again more pronounced on day 8 than on day 11 , as in the incomplete factorial design, there was no formally significant interaction between CP supply and time $(P=0.063)$.

The experimental design created the required conditions in order to test our hypotheses. In the present experiment, restricted feeding at $90 \%$ of the achieved feed intake observed in previous experiments avoided increased feed intake, which has been observed when animals are offered foods with higher CP content. The success of the experimental design is further evidenced by the small numbers of food refusal that occurred across feeding treatments and the consequently similar level of ME intake at increasing levels of CP intake, within each of the two different planes of ME supply (Fig. 1). With regard to performance data, the lower level of ME supply resulted in higher dam weight loss and lower litter gain. This is consistent with previous findings on the effects of energy nutrition on lactational performance of rats ${ }^{(18,19)}$. At the same time, increased CP supply resulted in smaller dam weight loss and larger litter weight gain. Since the last increment of CP supply did not further increase lactational performance, the range of $\mathrm{CP}$ supply achieved ranged from scarce to more than adequate. However, it cannot be discounted that the ME supply was still limiting at the highest level of ME supply used, as only two levels of ME were used.

Lactation imposes significant protein demands on mammals ${ }^{(14)}$. At times of dietary protein scarcity, additional protein may be derived from labile body protein. However, the amount of labile body protein that can be mobilised is limited $^{(13)}$, and this limitation was further exacerbated by feeding low-protein food during late gestation. At the same time, parasitised hosts would be expected to have additional protein requirements to activate or maintain an effective protective response to parasites ${ }^{(6)}$. This is because the effector mechanisms of the immune response are highly proteinaceous in nature and inflammation and immune system activation are characterised by the synthesis of specific proteins that play crucial roles in the defence of the host against pathogens and the modulation of the immune response ${ }^{(20,21)}$. Thus, feeding foods with a sufficiently low CP content to lactating parasitised hosts, as in the present experiment, would be expected to result in protein scarcity, with penalties on both lactational performance and expression of immunity to parasites. We considered changes in the number of adult nematodes in the small intestine and EIC to be the result of changes in the degree of expression of immunity to $N$. brasiliensis, as they provide the ultimate measure on how the host copes with the challenge ${ }^{(22)}$. Increasing dietary $\mathrm{CP}$ supply resulted in

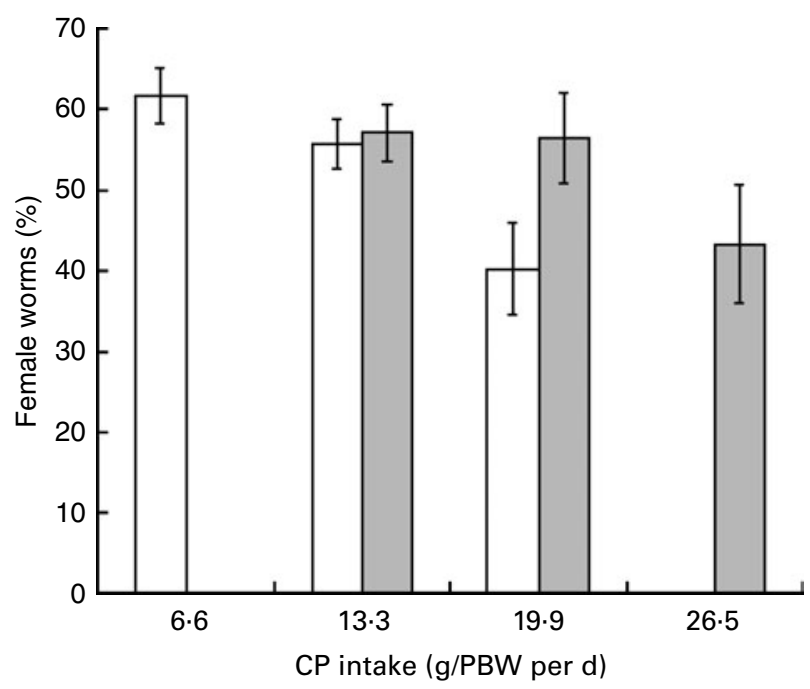

Fig. 6. Percentage of female worms in worm burden arising from re-infection with Nippostrongylus brasiliensis in lactating rats at four levels of dietary crude protein (CP) and two levels of metabolisable energy supply (1.05 and $1.40 \mathrm{MJ} / \mathrm{kg}$ parturition body weight (PBW per d); $\square$, low energy; $\square$, high energy. Values are means with their standard errors represented by vertical bars. 
a significant reduction in worm burden. This agrees with results from studies with periparturient mammalian hosts, including rats ${ }^{(7,8)}$, ewes ${ }^{(23-26)}$ and dairy goats ${ }^{(27,28)}$. However, to our knowledge, the present experiment is the first to have assessed independently the effects of $\mathrm{CP}$ and ME supply on resistance to parasites in a non-ruminant periparturient model.

Increased CP supply did not affect EIC, although there was a substantial decrease at the higher levels of CP supply. The absence of a significant nutritional sensitivity of EIC in the presence of such effects on total worm burden concurred with substantially larger variation (see Fig. 5). While it cannot be excluded that this may have arisen to some extent from the lower than expected number of replicates, and variation in fecundity in response to dietary treatments, we have discussed previously that this may arise from the relatively large numbers of steps involved in the nematode egg counting technique used ${ }^{(12)}$. Perhaps, to some extent, this variation could have been reduced through repeated measures of FECs and assessment of daily nematode egg excretion during secondary infection. However, earlier attempts suggest that the highly digestible nature of the semi-synthetic foods used would not have allowed consistent production of the relatively large volumes of faeces required for such purpose ${ }^{(22)}$.

In addition to reducing worm burden, the increasing level of $\mathrm{CP}$ supply resulted in a reduced percentage of female worms in the worm burdens, especially at the lower level of ME supply. Increased CP supply reduced the percentage of female worms not only in earlier studies using the same host-parasite system ${ }^{(7)}$, but also following protein supplementation of sheep infected with Haemonchus contortus ${ }^{(29)}$. It has been shown that female adult nematodes are usually expelled at a higher rate than male adult nematodes ${ }^{(30,31)}$ and that rats infected solely with female adult $N$. brasiliensis develop a stronger immunity than rats infected with male worms $^{(32)}$. Taken together, these observations suggest that the expression of immunity may be more effective towards female than towards male $N$. brasiliensis ${ }^{(12)}$. Since female worms are longer and heavier than male worms ${ }^{(33)}$, it would be reasonable to assume that the mean worm length and the weight of the worm burden in the dams receiving lower protein was larger than in the dams fed higher levels of protein. For abomasal infections in sheep, it has been suggested that hosts control worm mass rather than worm number, since longer and heavier worms may cause more damage to the host ${ }^{(34)}$. If such arguments hold for small-intestinal infections as well, then having a worm burden with shorter and lighter worms would have been beneficial to the rats fed higher levels of protein.

In the present experiment, moderate ME restriction imposed during lactation did not affect worm burdens, the worm sex ratio or the number of nematode EIC. Studies in ruminants have likewise shown that gastrointestinal parasitism is not sensitive to moderate changes in ME supply ${ }^{(23,35)}$. Activation and maintenance of an immune response are expected to be energetically demanding processes ${ }^{(36)}$ and immune cells require high levels of glucose ${ }^{(37)}$. This has been evidenced by the lower amount of fat deposits in infected mice compared with their uninfected counterparts ${ }^{(38,39)}$. It should be noted that the high energetic demand for milk synthesis in lactating mammals can, at least to some degree, be met through mobilisation of maternal adipose tissue ${ }^{(40)}$. An energy restriction during lactation results in increased body fat mobilisation in many species of mammals, including rats ${ }^{(41-45)}$. It cannot be excluded that the effects of dietary ME supply on worm burden were not observed because the likely higher rate of body fat mobilisation in the low-ME dams may have provided sufficient ME to overcome ME scarcity for the expression of immunity. The effects of energy (caloric) restriction on resistance to parasites have also been assessed in growing rodents ${ }^{(46-48)}$. In contrast to our findings, energy restriction was consistently associated in these studies with higher worm burden. Careful consideration of the extent and the duration of the energy restriction imposed in these experiments suggests that these were substantially greater and longer than those used in the present study. For example, Koski et $a{ }^{(46)}$ applied an energy restriction of up to $25 \%$ for 6 weeks; Kristan ${ }^{(47)}$ imposed an energy restriction of $40 \%$ for almost 7 months, and Lunn et al. ${ }^{(48)}$ used an energy restriction of $40 \%$ for 3 weeks. In contrast, we imposed a moderate ME restriction of $25 \%$ for no longer than $11 \mathrm{~d}$. Growing animals, when nutritionally restricted, mobilise fat while growing protein or retaining their protein reserves ${ }^{(49,50)}$, while severe and prolonged feed restriction leads to combined fat and protein losses ${ }^{(51)}$. Thus, we cannot exclude the possibility that a more severe ME restriction could also have affected host resistance to parasites in our model system.

Re-infection with $N$. brasiliensis did not affect achieved DM intake and maternal body weight gain but reduced litter body weight gain (a proxy for milk production) during lactation with the consequence of infection on litter body weight being more pronounced for feeding treatments 1 and 2 (Fig. 3(b)). This suggests that infection can reduce lactational performance provided that the level of protein-energy malnutrition is sufficiently low. Indeed, at higher levels of ME intake, re-infection with $N$. brasiliensis did not affect litter weight gain $^{(7,8)}$. Anorexia has not been observed in the aforementioned studies using the same host-parasite model, which is consistent with the view that it mainly characterises primary infections ${ }^{(52,53)}$. The absence of a systematic effect of infection on litter weight in the rats during lactation supports the view that scarce nutrient allocation to milk production takes priority over expression of immunity in parasite-immunised periparturient mammals ${ }^{(20)}$. This is because in the converse situation, infection would have been expected to penalise litter growth in any nutritional environment, and not only when both $\mathrm{CP}$ and ME supply are sufficiently low (treatments 1 and 2) to reduce resilience ${ }^{(7)}$. Variable effects of nematode infection on food intake and/or dam and pup performance have been observed in other host-parasite systems ${ }^{(54-56)}$. However, these experiments are not considered comparable to the present experiment, as they involved parasite-naïve animals. Such hosts are expected to prioritise resource allocation to cover the nutritional requirements of expression of immunity towards parasites over those of maintenance and growth ${ }^{(6)}$.

In conclusion, the present results support the view that the degree of PPRI to $N$. brasiliensis is sensitive to changes 
in protein but not moderate energy supply. This is shown by a decrease in the worm burden, which was achieved in the present experiment with increasing levels of protein intake. Future work may focus on the involvement of specific, essential amino acids in these responses, as there is an increasing body of evidence for amino acid-specific effects on host immune responses ${ }^{(57)}$. Increasing $\mathrm{CP}$ intake resulted in a reduction of the percentage of female worms in the remaining worm burden, which could suggest a more effective expression of immunity towards female worms. This could be beneficial to hosts, as female worms are larger and heavier than male worms and may cause more damage to parasitised hosts. The performance data suggest that secondary parasitic infections may have significant effects on host lactational performance, especially at times of protein-energy malnutrition.

\section{Acknowledgements}

The authors thank the staff of the March Building at the University of Edinburgh for animal husbandry, and Ian Nevison (Biomathematics and Statistics Scotland) for statistical advice. The present work was supported by the Biotechnology and Biology Sciences Research Council (BBSRC). The Scottish Agricultural College and the Moredun Research Institute received support from the Scottish Government, Rural and Environmental Research and Analysis Directorate. P. S. is grateful to the Hellenic State Scholarship Foundation for the provision of a postgraduate scholarship. None of the authors has a conflict of interest in relation to the present study. The present study has resulted from the postgraduate studies of P. S. and is part of his $\mathrm{PhD}$ thesis. All other authors have contributed equally to the study.

\section{References}

1. Houdijk JGM, Jessop NS \& Kyriazakis I (2001) Nutrient partitioning between reproductive and immune functions in animals. Proc Nutr Soc 60, 515-525.

2. Barger IA (1993) Influence of sex and reproductive status on susceptibility of ruminants to nematode parasitism. Int $J$ Parasitol 23, 463-469.

3. Beasley AM, Kahn LP \& Windon RG (2010) The periparturient relaxation of immunity in Merino ewes infected with Trichostrongylus colubriformis: parasitological and immunological responses. Vet Parasitol 168, 60-70.

4. Coop RL \& Kyriazakis I (1999) Nutrition-parasite interaction. Vet Parasitol 84, 187-204.

5. Houdijk JGM \& Athanasiadou S (2003) Direct and indirect effects of host nutrition on ruminant gastrointestinal nematodes. In Proceedings of the Fourth International Symposium on the Nutrition of Herbivores, Mérida, Mexico, pp. 213-236 [L t' Mannetje, L Ramirez-Aviles, CA Sandoval-Castro and JC Ku-Vera, editors]. Merida: University of Yucatan Press.

6. Kyriazakis I \& Houdijk J (2006) Immunonutrition: nutritional control of parasites. Small Rumin Res 62, 79-82.

7. Houdijk JGM, Jessop NS, Knox DP, et al. (2005) Secondary infection of Nippostrongylus brasiliensis in lactating rats is sensitive to dietary protein content. Br J Nutr 93, 493-499.

8. Jones LA, Houdijk JGM, Knox DP, et al. (2009) Immunomodulatory effects of dietary protein during Nippostrongylus brasiliensis re-infection in lactating rats. Parasite Immunol 31, $412-421$.

9. Normanton H, Houdijk J, Jessop NS, et al. (2005) The effect of changes in nutrient demand on gastrointestinal parasitism in lactating rats. Proc Br Soc Anim Sci, p. 12.

10. Koski KG \& Scott ME (2001) Gastrointestinal nematodes, nutrition and immunity: breaking the negative spiral. Annu Rev Nutr 21, 297-321.

11. Donaldson J, van Houtert MFJ \& Sykes AR (1998) The effect of nutrition on the periparturient parasite status of mature ewes. Anim Sci 67, 523-533.

12. Houdijk JGM, Jessop NS, Knox DP, et al. (2003) Breakdown of immunity to Nippostrongylus brasiliensis in lactating rats. Br J Nutr 90, 809-814.

13. Pine AP, Jessop NS \& Oldham JD (1994) Maternal protein reserves and their influence on lactational performance in rats. BrJ Nutr 71, 13-27.

14. Friggens NC, Hay DEF \& Oldham JD (1993) Interactions between major nutrients in the diet and the lactational performance of rats. BrJ Nutr 69, 59-71.

15. Oldham JD \& Friggens NC (1989) Sources of variability in lactational performance. Proc Nutr Soc 48, 33-43.

16. Christie M \& Jackson F (1982) Specific identification of strongyle eggs in small samples of sheep feces. Res Vet Sci 32, 113-117.

17. Jones LA, Houdijk JGM, Sakkas P, et al. (2011) Dissecting the impact of protein versus energy host nutrition on the expression of immunity to gastrointestinal parasites during lactation. Int J Parasitol 41, 711-719.

18. Kliewer RL \& Rasmussen KM (1987) Malnutrition during the reproductive-cycle - effects on galactopoietic hormones and lactational performance in the rat. Am J Clin Nutr $\mathbf{4 6}$, 926-935.

19. Passos MCF, Ramos CF \& Moura EG (2000) Short and long term effects of malnutrition in rats during lactation on the body weight of offspring. Nutr Res 20, 1603-1612.

20. Coop RL \& Kyriazakis I (2001) Influence of host nutrition on the development and consequences of nematode parasitism in ruminants. Trends Parasitol 17, 325-330.

21. Le Floc'h N, Melchior D \& Obled C (2004) Modifications of protein and amino acid metabolism during inflammation and immune system activation. Livest Prod Sci 87, $37-45$.

22. Normanton H, Houdijk JGM, Jessop NS, et al. (2007) The effects of changes in nutritional demand on gastrointestinal parasitism in lactating rats. BrJ Nutr 97, 104-110.

23. Donaldson J, van Houtert MFJ \& Sykes AR (2001) The effect of dietary fish-meal supplementation on parasite burdens of periparturient sheep 1. Anim Sci 72, 149-158.

24. Houdijk JGM, Kyriazakis I, Jackson F, et al. (2003) Is the allocation of metabolisable protein prioritised to milk production rather than to immune functions in Teladorsagia circumcincta-infected lactating ewes? Int J Parasitol 33, 327-338.

25. Houdijk JGM, Kyriazakis I, Jackson F, et al. (2005) Effects of protein supply and reproductive status on local and systemic immune responses to Teladorsagia circumcincta in sheep. Vet Parasitol 129, 105-117.

26. Kahn LP, Knox MR, Gray GD, et al. (2003) Enhancing immunity to nematode parasites in single-bearing Merino ewes through nutrition and genetic selection. Vet Parasitol 112, 211-225.

27. Chartier C, Etter E, Hoste H, et al. (2000) Effects of the initial level of milk production and of the dietary protein intake on the course of natural nematode infection in dairy goats. Vet Parasitol 92, 1-13. 
28. Etter E, Chartier C, Hoste H, et al. (1999) The influence of nutrition on the periparturient rise in fecal egg counts in dairy goats: results from a two-year study. Rev Med Vet 150, 975-980.

29. Wallace DS, Bairden K, Duncan JL, et al. (1995) Influence of supplementation with dietary soyabean meal on resistance to haemonchosis in Hampshire down lambs. Res Vet Sci 58, 232-237.

30. Africa CM (1931) Studies on the host relations of Nippostrongylus muris. J Parasitol 18, 1-13.

31. Jarrett EEE, Jarrett WFH \& Urquhart GM (1968) Quantitative studies on the kinetics of establishment and expulsion of intestinal nematode populations in susceptible and immune hosts Nippostrongylus brasiliensis in the rat. Parasitology $\mathbf{5 8}, 625-639$.

32. Ogilvie BM (1965) Role of adult worms in immunity of rats to Nippostrongylus brasiliensis. Parasitology 55, 325-335.

33. Kassai T (1982) Handbook of Nippostrongylus brasiliensis (nematode). Budapest: Commonwealth Agricultural Bureaux.

34. Stear MJ, Strain S \& Bishop SC (1999) How lambs control infection with Ostertagia circumcincta. Vet Immunol Immunopathol 72, 213-218.

35. Bown MD, Poppi DP \& Sykes AR (1991) The effect of post-ruminal infusion of protein or energy on the pathophysiology of Trichostrongylus colubriformis infection and body composition in lambs. Aust J Agric Res 42, 253-267.

36. Colditz IG (2008) Six costs of immunity to gastrointestinal nematode infections. Parasite Immunol 30, 63-70.

37. Fox CJ, Hammerman PS \& Thompson CB (2005) Fuel feeds function: energy metabolism and the T-cell response. Nat Rev Immunol 5, 844-852.

38. Coltherd JC, Bünger L, Kyriazakis I, et al. (2009) Genetic growth potential interacts with nutrition on the ability of mice to cope with Heligmosomoides bakeri infection. Parasitology 136, 1043-1055.

39. Kristan DM \& Hammond KA (2000) Combined effects of cold exposure and sub-lethal intestinal parasites on host morphology and physiology. J Exp Biol 203, 3495-3504.

40. Oftedal OT (2000) Use of maternal reserves as a lactation strategy in large mammals. Proc Nutr Soc 59, 99-106.

41. del Rosario Ayala M, Racotta R, Hernández-Montes $\mathrm{H}$, et al. (2006) Some metabolic effects on lactating rats of a lowenergy diet restricted in good-quality protein. Br J Nutr $\mathbf{9 6}$, 667-673.

42. Brendemuhl JH, Lewis AJ \& Peo ER (1987) Effect of protein and energy-intake by primiparous sows during lactation on sow and litter performance and sow serum thyroxine and urea concentrations. J Anim Sci 64, 1060-1069.

43. Brendemuhl JH, Lewis AJ \& Peo ER (1989) Influence of energy and protein-intake during lactation on body-composition of primiparous sows. J Anim Sci 67, 1478-1488.
44. Cowan RT, Robinson JJ, McHattie I, et al. (1980) The prediction of body composition in live ewes in early lactation from live weight and estimates of gut contents and total body water. J Agric Sci 95, 515-522.

45. Parmley KLS, Machado CR \& McNamara JP (1996) Rates of lipid metabolism in adipose tissue of pigs adapt to lactational state and dietary energy restriction. J Nutr 126, $1644-1656$.

46. Koski KG, Su Z \& Scott ME (1999) Energy deficits suppress both systemic and gut immunity during infection. Biochem Biophys Res Commun 264, 796-801.

47. Kristan DM (2007) Chronic calorie restriction increases susceptibility of laboratory mice (Mus musculus) to a primary intestinal parasite infection. Aging Cell 6, 817-825.

48. Lunn PG, Northrop CA \& Wainwright M (1988) Hypoalbuminemia in energy-malnourished rats infected with Nippostrongylus brasiliensis (Nematoda). J Nutr 118, 121-127.

49. Kyriazakis I \& Emmans GC (1992) The effects of varying protein and energy intakes on the growth and body composition of pigs. 1. The effects of energy intake at constant, high protein intake. BrJ Nutr 68, 603-613.

50. Kyriazakis I \& Emmans GC (1992) The effects of varying protein and energy intakes on the growth and body composition of pigs. 2. The effects of varying both energy and protein intake. BrJ Nutr 68, 615-625.

51. Hornick JL, Van Eenaeme C, Gerard O, et al. (2000) Mechanisms of reduced and compensatory growth. Domest Anim Endocrinol 19, 121-132.

52. Kyriazakis I, Tolkamp BJ \& Hutchings MR (1998) Towards a functional explanation for the occurrence of anorexia during parasitic infections. Anim Behav 56, 265-274.

53. Kyriazakis I (2010) Is anorexia during infection in animals affected by food composition? Anim Feed Sci Technol 156, 1-9.

54. Kristan DM (2002) Effects of intestinal nematodes during lactation: consequences for host morphology, physiology and offsprings mass. J Exp Biol 205, 3955-3965.

55. Odiere MR, Koski KG, Weiler HA, et al. (2010) Concurrent nematode infection and pregnancy induce physiological responses that impair linear growth in the murine foetus. Parasitology 137, 991-1002.

56. Willis C \& Poulin R (1999) Effects of the tapeworm Hymenolepis diminuta on maternal investments in rats. Can J Zool 77, 1001-1005.

57. Li P, Yin YL, Li D, et al. (2007) Amino acids and immune function. Br J Nutr 98, 237-252.

58. Astrup A \& Tremblay A (2009) Energy metabolism. In Introduction to Human Nutrition, 2nd ed., pp. 31-48 [MJ Gibney, SA Lanham-New and HH Cassidy Vorster, editors]. Oxford: Wiley-Blackwell. 